\title{
The limb deformity gene is required for apical ectodermal ridge differentiation and anteroposterior limb pattern formation
}

\author{
Rolf Zeller, ${ }^{1}$ Laurie Jackson-Grusby, and Philip Leder \\ Department of Genetics, Harvard Medical School, Howard Hughes Medical Institute, Boston, Massachusetts 02115 USA
}

\begin{abstract}
To gain insight into the role of the limb deformity $(l d)$ gene in limb morphogenesis, we examined the morphologic details of early embryonic limb formation in the mutant $1 d / 1 d$ mouse. Initial morphological differences between wild-type and homozygous $1 d$ embryos are apparent during early gestational day 10, a time period during which anteroposterior limb morphogenesis occurs. As a result of a shortened anteroposterior axis, the mutant limb bud appears more pointed than its wild-type counterpart. In addition, the apical ectodermal ridge (AER), a structure crucial to both proximodistal and anteroposterior limb development, fails to differentiate properly in mutant $I d$ embryos. Consistent with these observations, molecular analysis of the limb promordia shows that the limb ectoderm contains a level of $l d$ transcripts fivefold higher relative to its mesenchyme. Furthermore, expression of $l d$ transcripts in other parts of the developing embryo and in primitive streak embryos (gestational day 7) suggests possible roles for this gene in the earliest determinative events of morphogenesis. These data lead us to conclude that $l d$ gene products are required for both proper AER differentiation and anteroposterior pattern formation in limb mesenchyme.
\end{abstract}

[Key Words: Apical ectodermal ridge; embryogenesis; limb development; limb deformity mutation; pattern formation]

Received June 13, 1989; revised version accepted August 7, 1989.

The establishment of the anteroposterior and proximodistal axes in the developing limb is one of the best studied pattern-forming processes in vertebrates. Classical experiments have shown that the mechanisms underlying limb pattern formation are evolutionarily conserved (for review, see Tickle 1980; Brockes 1989). These experiments led to models proposing that the two major axes in the limb bud are established by a series of ectodermal-mesenchymal interactions. Two morphogenetically active regions have been identified in these studies. One, the apical ectodermal ridge (AER), is a specialized thickened epithelial structure at the growing tip of the limb bud. Its interactions with the underlying mesenchyme are required to establish both the proximodistal and anteroposterior axis of the limb (for review, see Kelley and Fallon 1981; Fallon et al. 1983). The second, the polarizing region (or ZPA), is a group of mesenchymal cells at the posterior margin of the limb bud that has been proposed to act as a signaling region to specify the anteroposterior limb pattern (for review, see Tickle 1980). Wolpert (1969) suggested that anteroposterior polarity is established through a concentration gradient of a morphogen produced by the polarizing re-

'Present address: EMBL, D-6900 Heidelberg, FRG. gion. Retinoic acid has been proposed to be this morphogen (Tickle et al. 1985; Thaller and Eichele 1987), acting by exerting its primary effect on the limb mesenchyme (Tickle et al. 1989).

To understand these developmental processes at a molecular level, it is crucial to identify and characterize the genes involved. In mice, numerous mutations affecting normal development of the limb have been described (Grueneberg 1963). The isolation of some of these genes recently has become feasible through chance insertional mutagenesis in transgenic mice (Woychik et al. 1985; McNeish et al. 1988). Woychik et al. (1985) were able to isolate the endogenous sequences disrupted by a transgene insertion causing a mutation at the limb deformity (ld) locus. They showed that this recessive mutation $1 d^{\text {Hd }}$ is allelic to two previously isolated spontaneous $1 d$ alleles, $1 d^{\mathrm{J}}$ and $1 d^{\mathrm{OR}}$ (Cupp 1960; Green 1962, 1968). All three alleles are recessive and show a pleiotropic phenotype. They display synostosis of the long bones of all limbs, oligodactyly and syndactyly of the bones of hand and foot plates (Green 1968; Kleinebrecht et al. 1982; Woychik et al. 1985) and a high frequency of uni- and bilateral renal aplasias (Kleinebrecht et al. 1982; R. Maas and P. Leder, unpubl.). No other defects have been identified at the gross-morphological level in any of the three 
ld alleles. This suggests that these independently derived mutations may interfere specifically with anteroposterior limb pattern formation and organogenesis of the kidney.

Molecular analysis identified an evolutionarily conserved gene within the sequences flanking the transgene insertion site (R.P. Woychik, R. Maas, T.F. Vogt, R. Zeller, and P. Leder, in prep.). Differential polyadenylation and alternative splicing of this gene yields a major set of transcripts of $\sim 13,7$, (both in adult and embryonic tissues), and $5 \mathrm{~kb}$ (adult tissues only), as well as smaller transcripts of variable size and distribution. Expression of these major transcripts is abolished in two independently isolated $1 d$ alleles, providing strong evidence that the transcripts arise from the $1 d$ gene. In particular, an identified open reading frame (ORF) is disrupted by the transgene insertion in the $1 d^{\mathrm{Hd}}$ allele. These data suggest further that the $1 d^{\mathrm{Hd}}$ mutation is a reduction or loss-offunction mutation (R. Maas, R. Zeller, R.P. Woychik, T.F. Vogt, and P. Leder, in prep.).

To gain insight into the role of the $1 d$ gene at the cellular and molecular level, we have analyzed the limb phenotype and the expression pattern of the $1 d$ gene. A comparative analysis of wild-type and mutant $1 d \mathrm{em}$ bryos during the early stages of limb bud development shows that the anteroposterior pattern of gestational day-10 and older mutant limb buds is affected severely. In contrast, the establishment of the proximodistal limb pattern seems unaffected in mutant embryos. Furthermore, differentiation of the AER fails to occur properly in mutant $1 d$ embryos. In addition, we find the level of $l d$ transcripts in the ectoderm approximately fivefold higher, relative to the mesenchyme of wild-type gestational day-10 limb buds. We discuss our findings with respect to the mesenchymal-ectodermal interactions involving the AER, which mediate anteroposterior limb pattern formation.

\section{Results}

\section{Id mutations disrupt anteroposterior $\operatorname{limb}$ pattern formation}

Forelimb buds appear as distinct structures during early gestational day 9 of mouse embryogenesis (defining day of vaginal plug formation as gestational day 0 |, whereas hindlimb buds first become apparent during late gestational day 9 (for review, see Rugh 1968). The anteroposterior limb pattern is determined during the early stages of limb bud outgrowth (gestational day 10 and 11 ; Kochhar 1977) when a morphogenetically active polarizing zone is present (Tickle et al. 1976). During later outgrowth, the mesenchymal condensations that determine the positions of the prospective limb bones, carpals, and digits form and differentiate (Rugh 1968; Kochhar 1977).

We conducted a detailed study of the establishment of the mutant phenotype to determine whether the mutant ld phenotype is caused by a failure to properly determine the initial anteroposterior pattern. Heterozygous males and females of the $1 d^{\mathrm{Hd}}$ mouse strain (Woychik et al. 1985) were mated to obtain timed pregnancies. Starting at gestational day 10, embryos were collected individually, with DNA being prepared from their extraembryonic membranes to determine their genotype (using the probes shown in Fig. 1F; see Materials and methods).

Visual comparison of mutant $\left(1 d^{\mathrm{Hd}} / l d^{\mathrm{Hd}}\right)$ and phenotypically wild-type $\left(1 d^{\mathrm{Hd}} /+\right.$ or $\left.+/+\right)$ day-10 embryos, using a dissecting microscope, reveals small but consistent differences in the shape of their limb buds. The limb buds of the vast majority of all homozygous $l d$ embryos at this stage are slightly narrower in their anteroposterior width, leading to a more pointed appearance of mutant than wild-type limb buds (Fig. 1A-C; Table 1; Fig. 4). We find an $87 \%$ correlation between the mutant phenotype (Fig. 1B) and homozygous mutant genotype (Table 1) by independent determination of phenotypes and genotypes of 251 gestational day-10 embryos.

The embryos shown in Figure 1, A and B are developmentally matched examples (see Materials and methods) of a wild-type (Fig. 1A) and mutant (Fig. 1B) gestational day-10 embryo. A tracing of the wild-type embryo (Fig. 1A) is shown in Figure 1C. The shaded areas in Figure $1 \mathrm{C}$ represent the size of the limb buds of a homozygous $1 d^{\text {Hd }}$ embryo shown in Figure 1B to reveal the small but significant shortening of the anteroposterior axis of the mutant limb buds, with respect to their wild-type counterparts. The difference at this early stage is generally more visible in the forelimb than in the hindlimb bud. This is due to the slightly more advanced developmental stage of the forelimb bud (Rugh 1968). The anteroposterior width of the forelimb bud at its base was measured from photographs of six pairs of phenotypically wildtype and mutant $l d^{\text {Hd }}$ day-10 embryos (data not shown). These measurements reveal that the anteroposterior axis of mutant forelimb buds is, on average, $\sim 17 \%$ $( \pm 6 \%)$ shorter than its wild-type counterpart. These data demonstrate that the minor but consistent differences seen are a consequence of the $1 d$ mutation.

By gestational day 11, the differences between wildtype and mutant limb buds are more striking (Fig. 1D and $\mathrm{E}$ ). In all cases (27 $1 d^{\mathrm{Hd}} / 1 d^{\mathrm{Hd}}$ embryos analyzed), the anteroposterior limb bud axis is clearly shorter in mutant $1 d^{\text {Hd }}$ embryos. The developing hand plates of all four limbs are reduced to rudiments in mutant embryos (Fig. $1 \mathrm{E}$. Analysis of embryos of the $1 d^{\mathrm{J}}$ and $l d^{\mathrm{OR}}$ mouse strains gave identical results (data not shown).

\section{Reductions and fusions of skeletal limb primordia in homozygous ld embryos}

During gestational days 11 and 12 , the limb skeletal primordia become apparent as distinct mesenchymal condensations. Differentiating chondrocytes within these condensations secrete a cartilage matrix that models the pattern of the prospective limb skeletal elements. During gestational day 14 , erosion of the cartilage matrix by osteoclasts begins. Osteoblasts replace this 

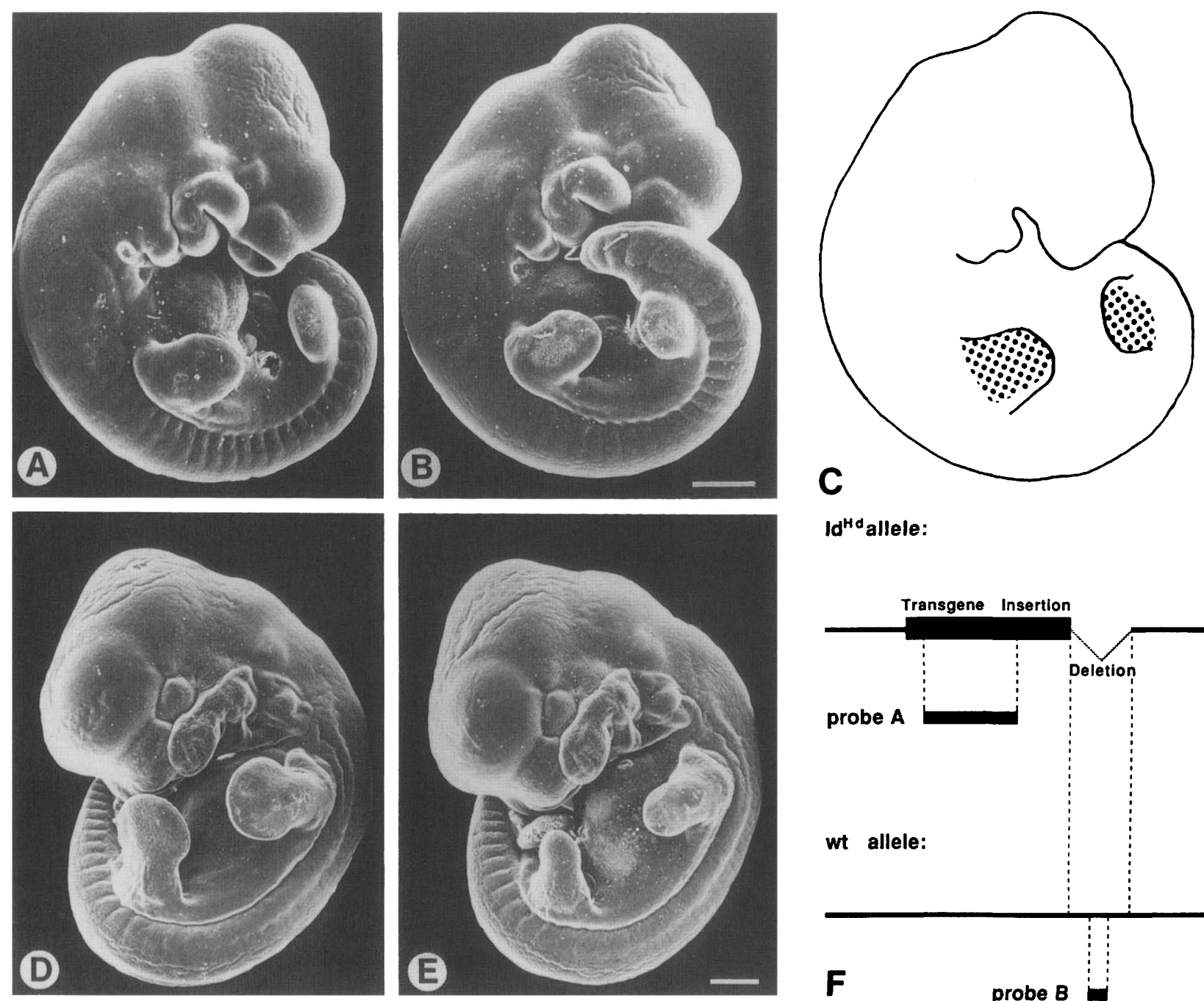

Id ${ }^{\mathrm{H} d a l l e l e:}$

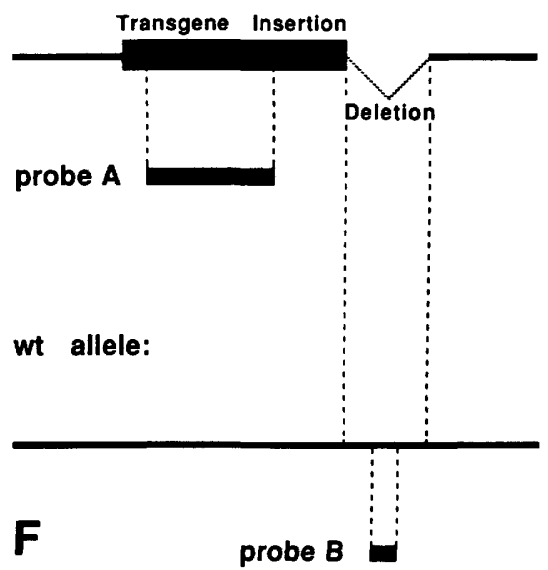

Figure 1. Establishment of the $1 d$ phenotype during gestational day 10 and 11 of embryogenesis. $(A)$ SEM micrograph of a phenotypi-

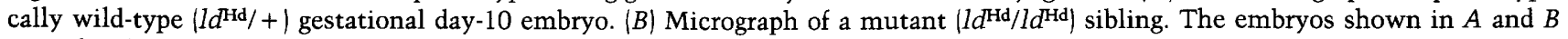
were developmentally matched, as described in Materials and methods. $(C)$ Tracing of wild-type embryo shown in $A$. Stippled areas indicate the size of the mutant fore- and hindlimb bud of the embryo shown in $B$. Bar, $500 \mu \mathrm{m}(A-C)$. (D) SEM micrograph of a wild-type $\left(+1+\mid\right.$ gestational day- 11 embryo. $(E)$ Micrograph of a developmentally matched mutant $\left(1 d^{\mathrm{Hd}} / 1 d^{\mathrm{Hd}}\right)$ sibling. Bar, $500 \mu \mathrm{m}(D$ and $E)$. $(F)$ Scheme of probes (not drawn to scale) used to determine the genotype of embryos from DNA isolated from their extraembryonic membranes.

matrix by deposition of bone, which can be visualized in ossification centers (Rugh 1968). To study the effects of the shortened anteroposterior axis on the pattern of limb skeletal primordia, cartilage and skeletal stains of limb buds were analyzed.

The number of digit primordia in mutant gestational day-12 limb buds is reduced in comparison to their wildtype counterparts $\left(6\right.$ homozygous $1 d^{\mathrm{Hd}}$ embryos analyzed). Cartilage elements corresponding to three or four of the five digits are stained in wild-type limb buds at this stage (Fig. 2A,C), whereas only one (hindlimb)- to two (forelimb)-digit primordia are formed in mutant limb buds (Fig. 2B,D). Comparing the digit primordia from several homozygous $1 d^{\text {Hd }}$ embryos of gestational day $11-15\left(161 d^{\mathrm{Hd}} / 1 d^{\mathrm{Hd}}\right.$ embryos analyzed $)$ reveals slight variations in their number or plane of anteroposterior fusion (data not shown). This is supported by a previous study describing many different phenotypic categories of anteroposterior digit pattern truncations in adult homozygous $1 d^{\text {T }}$ mice (Kleinebrecht et al. 1982).

Analysis of the primordia for long bones reveals that hindlimb buds of gestational day- 12 mutant $l d^{\mathrm{Hd}} \mathrm{em}-$ bryos $\left(61 d^{\mathrm{Hd}} / l d^{\mathrm{Hd}}\right.$ embryos analyzed $)$ always contain only one fused cartilage element (Fig. 2D) instead of the two found in their wild-type counterparts for tibia and fibula (Fig. 2C). In contrast, two distinct cartilage elements that are indistinguishable in their macroscopic appearance from wild-type ulna and radius primordia always form in mutant forelimb buds (Fig. 2A,B). The two cartilage elements of the developing mutant 
Zeller et al.

Table 1. Correlation between genotypes and phenotypes of gestational day-10 embryos of the $\mathrm{ld}^{\text {Hd }}$ mouse strain

\begin{tabular}{|c|c|c|c|c|c|}
\hline \multicolumn{2}{|c|}{ Genotype of embryos ${ }^{a}$} & $\begin{array}{c}l d^{\mathrm{Hd}} / 1 d^{\mathrm{Hd}}(n=56)^{\mathrm{a}} \\
(\%)\end{array}$ & 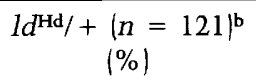 & $\begin{array}{c}+/+(n=52)^{\mathrm{b}} \\
(\%)\end{array}$ & $\begin{array}{c}\text { N.D. }(n=22)^{b, c} \\
(\%)\end{array}$ \\
\hline \multirow{3}{*}{$\begin{array}{l}\text { Limb bud } \\
\text { phenotype }\end{array}$} & wild-type & 11 & 84 & 88 & 50 \\
\hline & mutant & 87 & 4 & 4 & 14 \\
\hline & undefined ${ }^{\mathrm{d}}$ & 2 & 12 & 8 & 36 \\
\hline
\end{tabular}

${ }^{a}$ Genotypes and phenotypes of embryos were determined as described (see Results and Materials and methods). Examples of gestational day-10 embryos displaying wild-type or mutant limb bud phenotypes are shown in Fig. 1, A and B, respectively. The low percentage of discrepancies between genotypes and observed phenotypes is due to experimental error and not to reduced penetrance of the phenotype.

$\mathrm{b}(n)$ Number of embryos analyzed.

c(N.D.) Genotype was not determined due to low recovery of DNA. Genotypes were determined in $92 \%$ of all embryos analyzed (229 of 251 embryos).

$\mathrm{d}$ (Undefined phenotype) Limb bud phenotype was ambiguous or embryo was developmentally retarded (most cases).

forearm are always in much closer proximity than their wild-type counterparts (cf. Fig. 2A and B), possibly due to the shortened anteroposterior axis.

Because newborn and adult $1 d$ mutant mice always display complete synostosis of ulna and radius (Kleinebrecht et al. 1982; Woychik et al. 1985), it is important to determine when fusion of the two primordia occurs during embryogenesis. Analysis of day-13 embryos reveals no significant changes from gestational day 12 , except that cartilage elements appear more distinct due to advanced chondrification (data not shown). However, skeletal stains of day-14 embryonic limbs reveal proximal and distal fusion (synchondrosis) of the mutant ulna and radius primordia (Fig. 3B, large arrowheads; 5 $l d^{\mathrm{Hd}} / l d^{\mathrm{Hd}}$ embryos analyzed). As in wild-type limbs (Fig. 3A, small arrowheads), two distinct ossification centers are visible in the middle part of the mutant-fusing primordia (Fig. 3B, small arrowheads). Secondary fusion of the mutant ulna and radius primordia progresses during gestational day 15 and is completed during later gestational stages (data not shown). The results presented for the $l d^{\text {Hd }}$ strain are in agreement with the ones obtained studying the $1 d^{\text {J }}$ strain (Kleinebrecht et al. 1982; data not shown). These data demonstrate that the anteroposterior pattern of skeletal primordia in mutant limb buds is severely reduced.

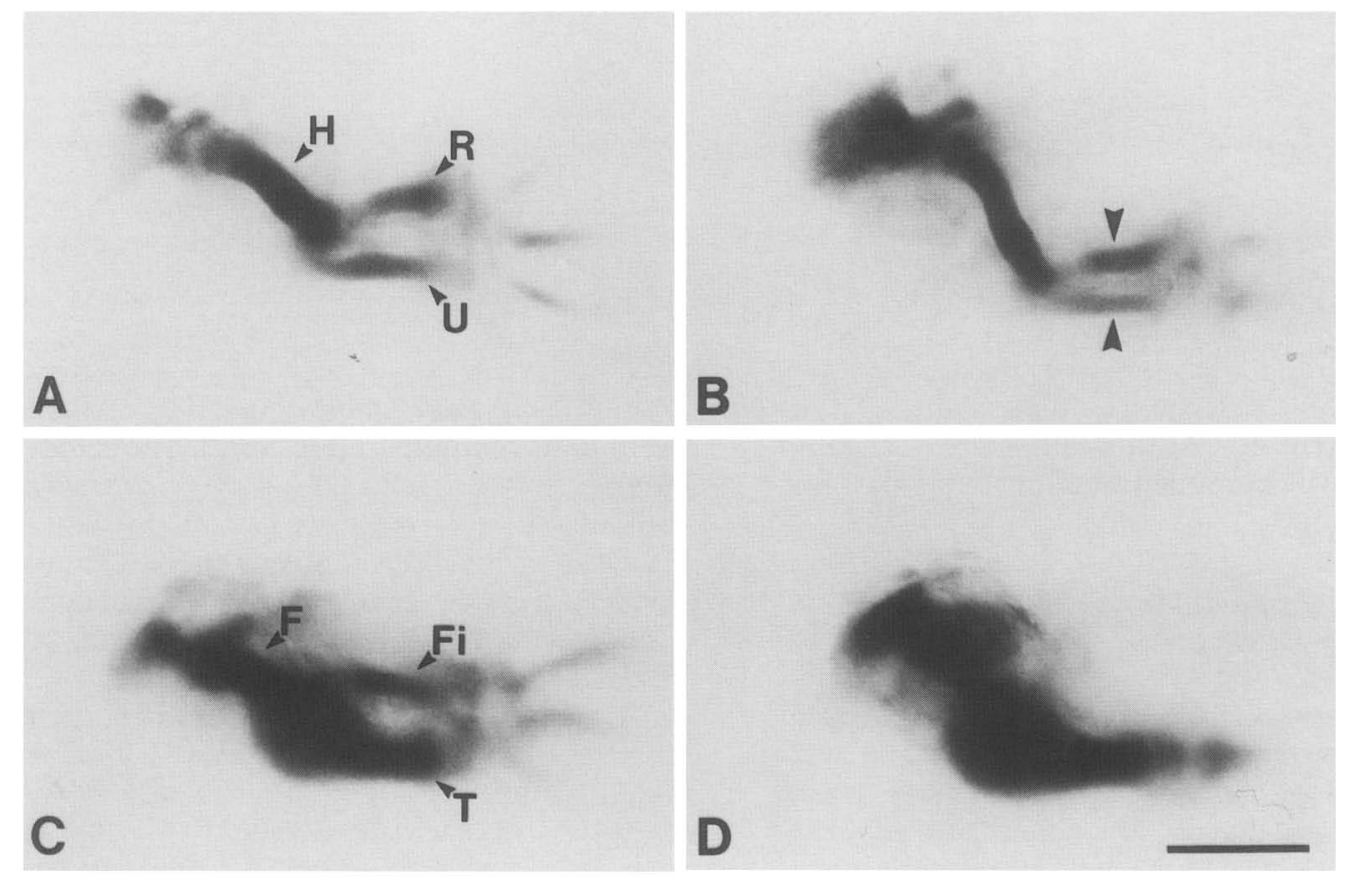

Figure 2. Alcian green staining of whole mounts of wild-type and mutant limbs buds of gestational day 12. Alcian green staining (Smith 1980) reveals the mesenchymal condensation forming skeletal primordia. (A) Forelimb bud of a wild-type $\left(l d^{\mathrm{Hd}} /+\right)$ embryo; $(\mathrm{H})$ humerus; (R) radius; (U) ulna. (B) Forelimb bud of a mutant $\left(1 d^{\mathrm{Hd}} / 1 d^{\mathrm{Hd}}\right)$ embryo. Arrowheads indicate closer proximity of the two mutant primordia in comparison to their wild-type counterparts in $A$. $(C)$ Hindlimb bud of the wild-type $\left(1 d^{\mathrm{Hd}} /+\right)$ embryo; $(\mathrm{F})$ femur; (Fi) fibula; (T) tibia. (D) Hindlimb bud of the mutant $\left(l d^{\mathrm{Hd}} / 1 d^{\mathrm{Hd}}\right)$ embryo. Note the presence of only one fused primordia for tibia and fibula whereas radius and ulna form as distinct elements. Bar, $500 \mu \mathrm{m}$. 


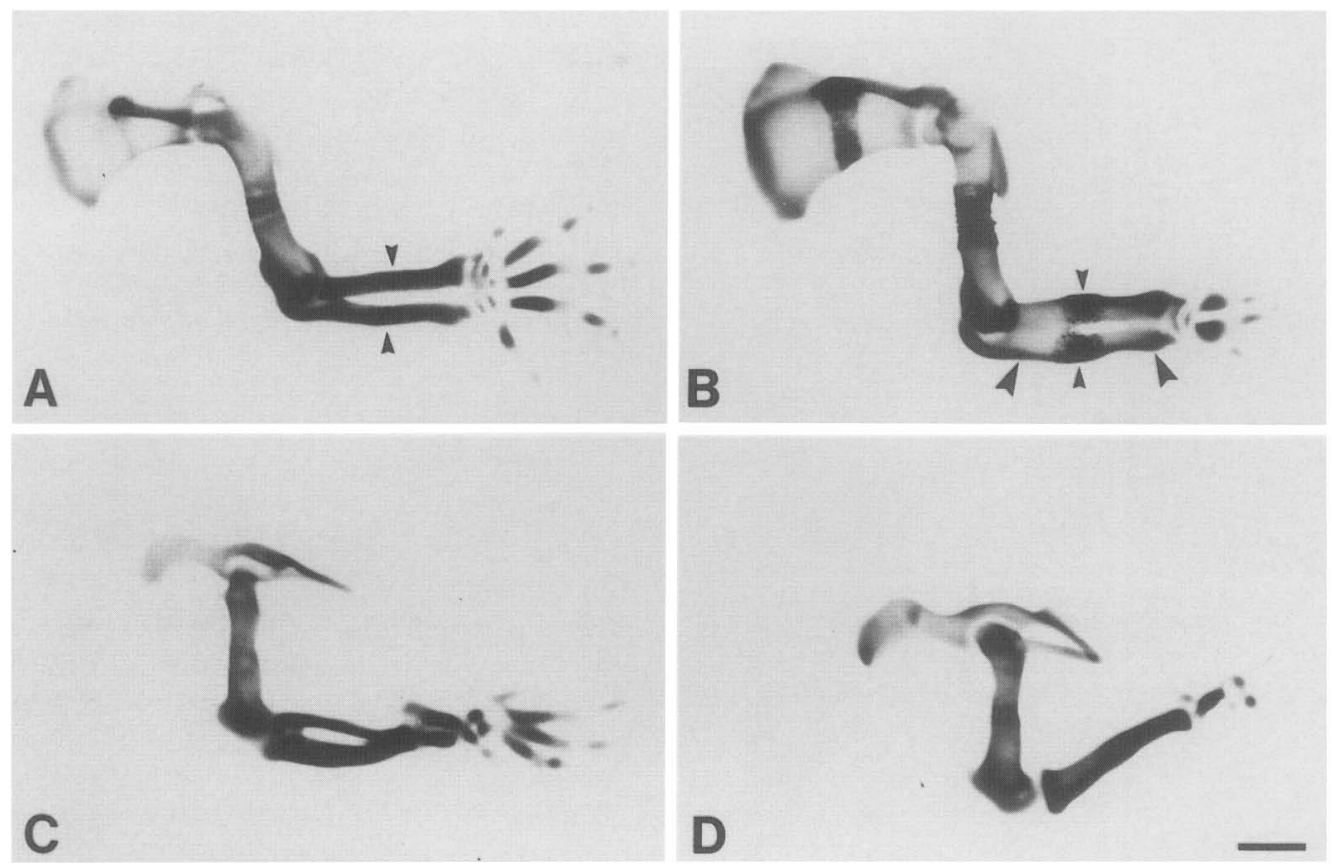

Figure 3. Alizarin redS/alcian blue staining of whole mounts of wild-type and mutant limbs of gestational day 14. Alizarin red S/alcian blue staining (McLeod 1980) differentiates cartilage and ossified bone matrix. $(A)$ Forelimb of a wild-type $(+/+)$ embryo. $(B)$ Forelimb of a mutant $\left(1 d^{\mathrm{Hd}} / 1 d^{\mathrm{Hd}}\right)$ embryo. Small arrowheads in $A$ and $B$ indicate ossification centers in long forearm bones. Large arrowheads in $B$ indicate proximal and distal fusion of the two mutant primordia. $(C)$ Hindlimb of the wild-type $(+/+)$ embryo. $(D)$ Hindlimb of the mutant $\left(1 d^{\mathrm{Hd}} / l d^{\mathrm{Hd}}\right)$ embryo. Note the complete fusion of tibia and fibula. Bar, $500 \mu \mathrm{m}$.

\section{Formation of a fully differentiated AER is disrupted in} mutant limb buds

The AER is a specialized epithelium running along the distal margin of the limb bud (Fig. 4A,C). To study the AER in detail, we examined seven pairs of mutant and wild-type embryos of gestational days 10 and 11 by scanning electron microscopy (SEM). Analysis of forelimb buds of early gestational day-10 wild-type embryos reveals a well-defined AER running anteroposterior along the tip (Fig. 4A). In contrast, no sign of ectodermal cells organized into a distinct AER is seen when forelimb buds of developmentally matched mutant $1 d^{\mathrm{Hd}} \mathrm{em}$ bryos are studied (Fig. 4B). At this early stage, an AER is not seen on wild-type or mutant hindlimb buds (data not shown).

Analysis of advanced gestational day-10 (Fig. 4C-F) and day-11 embryos (data not shown) reveals the presence of a morphologically defined, but severely altered, AER on all mutant limb buds (Fig. $4 \mathrm{D}, \mathrm{F}$ ). In striking contrast to the well-differentiated AER of wild-type limb buds (Fig. 4C,E; arrowheads), a much less distinct AER is seen extending anteroposterior along the rim of all of the mutant fore- and hindlimb buds analyzed (Fig. 4D,F; arrowheads|. A parallel study using developmentally matched wild-type and mutant embryos of the $1 d^{d}$ and $l d^{\mathrm{OR}}$ strains confirmed these results (data not shown).

To study the morphological differences between wildtype and mutant AERs at a cellular level, we performed a comparative histological analysis of late gestational day-10 embryos (Fig. 5). A well-defined wild-type AER consists of densely packed columnar cells forming thickened epithelium (Kelley and Fallon 1981; see Fig. $5 \mathrm{~A})$. Serial sections taken transverse to the anteroposterior axis (Fig. 5D) show a very uniform morphology and height of wild-type AERs (Fig. 5A,E). Analysis of mutant $1 d^{\text {Hd }}$ limb buds (5 embryos analyzed), however, reveals severe morphological alteration of the AER, which agrees with the SEM studies (Fig. 4). Most of the mutant AER appears flattened and poorly distinct in its cellular morphology from adjacent nonridge limb ectoderm (cf. Fig. 5A and B; see Fig. 5E). The characteristic dense packing and columnar morphology of cells forming a typical wild-type AER (Fig. 5A) are absent in the mutant counterpart (Fig. 5B,C). The ectodermal cells forming such a mutant AER have a rounded appearance indistinguishable from nonridge ectodermal cells, suggesting a defect in their differentiation or organization (Fig. 5B,C).

In addition to extensive stretches of flattened AER (Fig. 5B, E), patches of thickened AER (Fig. 5C, E) are also seen in mutant embryos. The height of such patches of thickened mutant AER can be similar to that of its wild-type counterpart (Fig. 5E). Its cells, however, appear rounded and fail to show any of the characteristic columnar morphology and organization of wild-type AER (cf. Fig. 5A and C). The ectodermal thickening of such morphologically aberrant patches of AER often extends further dorsoventral than wild-type AER (cf. arrowheads in Fig. 5A and Cl. The exact position and length of these patches varies among limb buds from different homozygous $1 d^{\text {Hd }}$ embryos or even among one 

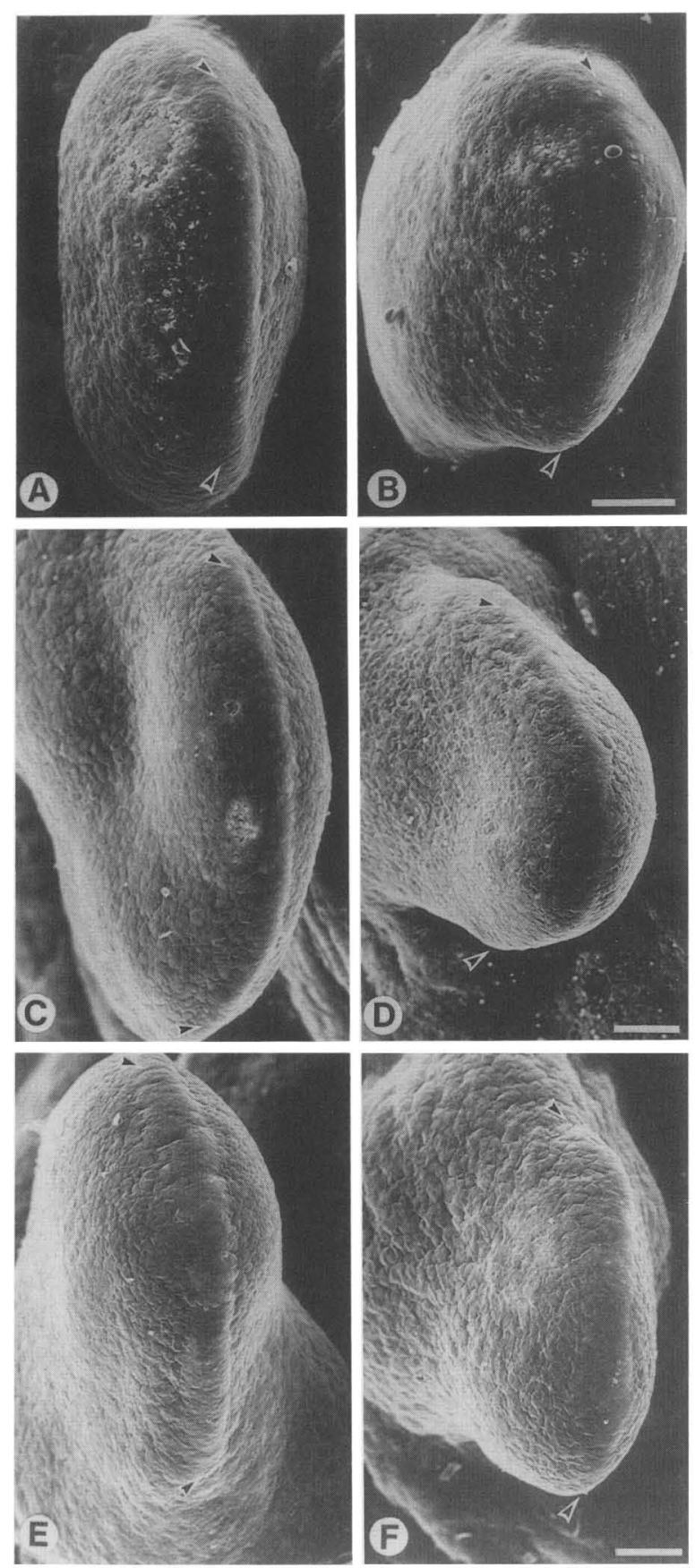

Figure 4. SEM analysis of wild-type and mutant AERs of gestational day-10 limb buds. Anterior limb bud margin is at the top $(A-E)$. Arrowheads indicate positions of wild-type and mutant AERs. (A) Forelimb bud of a wild-type $(+1+)$ early gestational day-10 embryo. (B) Forelimb bud of a developmentally matched mutant $\left(1 d^{\mathrm{Hd}} / l d^{\mathrm{Hd}}\right)$ early gestational day-10 embryo. Note that no morphologically distinct AER is visible in the mutant forelimb bud and that its anteroposterior axis is shorter in comparison to the wild-type. Bar, $100 \mu \mathrm{m}(A$ and $B \mid .(C)$ Forelimb bud of a phenotypically wild-type $\left(1 d^{\mathrm{Hd}} /+\mid\right.$ late gestational day-10 embryo. $(D)$ Forelimb bud of a developmentally matched mutant $\left(1 d^{\mathrm{Hd}} / 1 d^{\mathrm{Hd}}\right)$ late gestational day-10 embryo. $(E)$ Hindlimb bud of the wild-type $\left\{1 d^{\mathrm{Hd}} /+\right)$ late gestational day-10 embryo. $(F)$ Hindlimb bud of the mutant $\left(l d^{\mathrm{Hd}} / l d^{\mathrm{Hd}}\right)$ late gestational day-10 embryo. Bars, $100 \mu \mathrm{m}(C-F)$. particular embryo (Fig. 5E). The nature of the observed variation and its influence on establishing the truncated anteroposterior pattern are unknown at present (see Discussion). In addition, we noted areas of apparently necrotic mesenchymal cells in mutant limb buds (black and white arrowhead in Fig. 5C) but not in wild-type limb buds. Further analysis will be necessary to determine what role alterations of mesenchymal cells play in establishing the mutant $1 d$ limb phenotype.

\section{Expression of the ld gene in wild-type embryos and limb buds}

The results noted above indicate that the AER fails to differentiate properly in mutant $l d$ embryos. Therefore, the molecular defect noted in $1 d^{\mathrm{Hd}} / 1 d^{\mathrm{Hd}}$ animals must be linked to alterations in AER differentiation and anteroposterior pattern formation during limb development. R.P. Woychik et al. (in prep.) showed low levels of expression of two sets of $l d$ transcripts of $\sim 13$ and $7 \mathrm{~kb}$ in developing day-9 and older embryos. Due to the low levels of $l d$ transcripts, in situ hybridization experiments to study their temporal and spatial distribution have been unsuccessful to date (data not shown). To study the $l d$ transcription pattern, we performed a series of RNase protection experiments using dissected embryos of different gestational ages. An ld cDNA probe derived from the $3^{\prime}$ part of the ORF (Fig. $6 \mathrm{C}$ ) gives rise to a specific 150-nucleotide protected fragment in wildtype embryos (Fig. 6). Because this probe is derived from a region of the $1 d$ gene without alternative exon usage, the protected 150 nucleotide fragment is common to all major $1 d$ transcripts. No protection of this probe is found in homozygous $1 d^{\mathrm{Hd}}$ embryos, indicating that expression of the corresponding $l d$ transcripts is disrupted as a consequence of the transgene insertion (R. Maas et al., in prep.).

Earlier in development, $l d$ transcripts are detected in primitive streak embryos (gestational day 7), the earliest stage carefully analyzed thus far (Fig. 6A). Dissection of gestational day- 9 embryos into head, and upper and lower body fractions reveals no obvious preferential expression of the $1 d$ gene in any of the three compartments. The results obtained with this probe for gestational day-7 and older embryos were confirmed using several independent probes derived from regions more ${ }^{\prime}$ and $3^{\prime}$ of the $l d$ transcription unit (data not shown).

To determine whether there is any preferential or localized expression of the $1 d$ gene in either the mesenchymal or ectodermal compartment of gestational day-10 limb buds, a large number of wild-type limb buds were separated into ectodermal and mesenchymal tissues, as described in Materials and methods. Using the probe shown in Fig. 6C, a markedly higher level of $1 d$ transcripts was detected in the ectodermal compartment of the limb (Fig. 6B). Quantitation of three independent RNase protection experiments (see Materials and methods) reveals a level of $l d$ transcripts approximately fivefold $(4.6 \pm 1.5)$ higher in limb ectoderm, relative to limb mesenchyme. The lower, but significant, levels of 

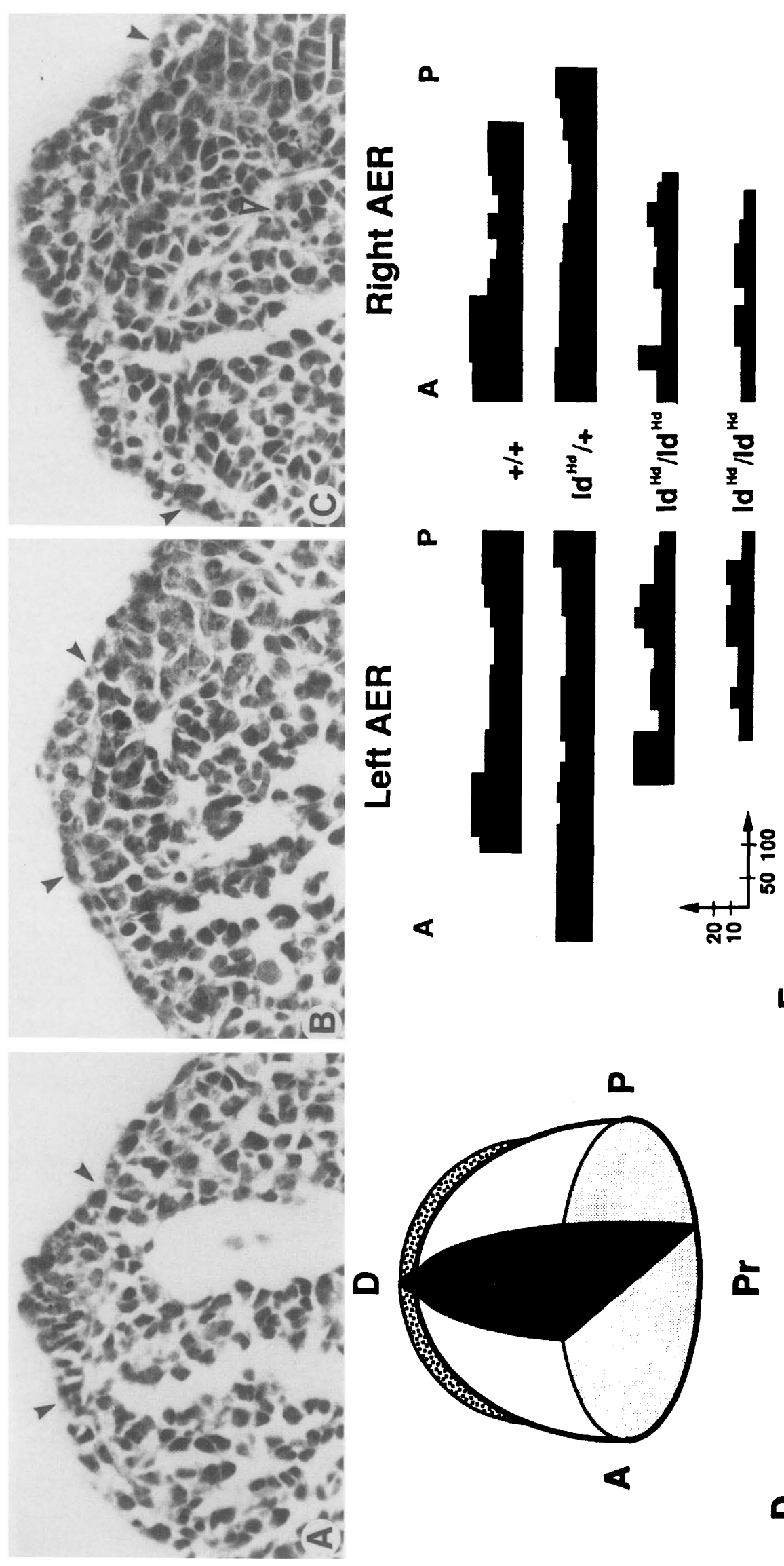

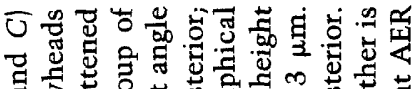

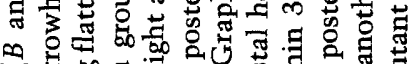

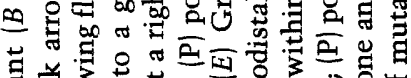
牙궁

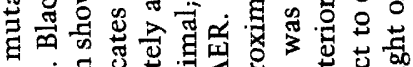

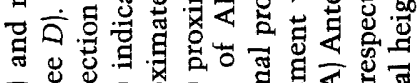

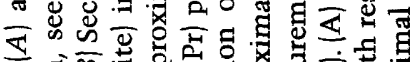

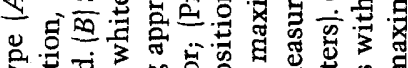

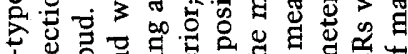

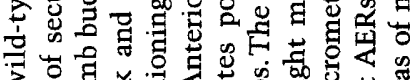

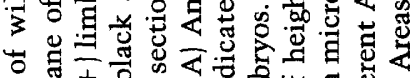

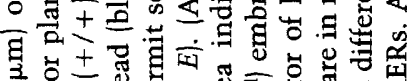

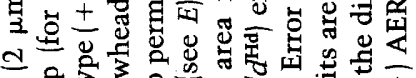

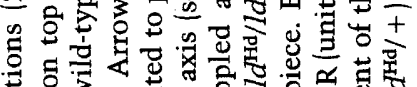

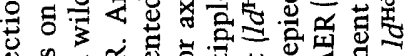

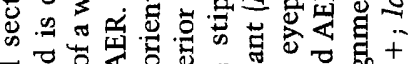

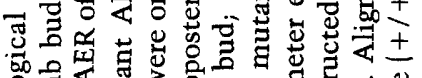

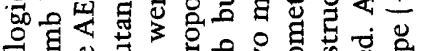

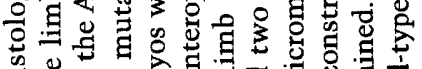

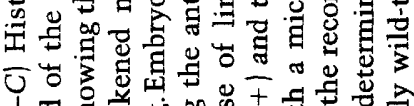

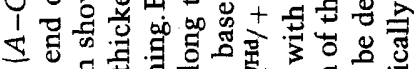

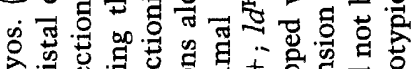

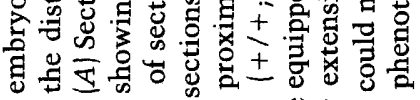

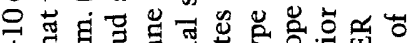

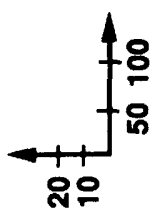

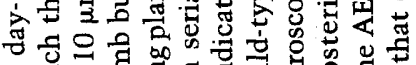

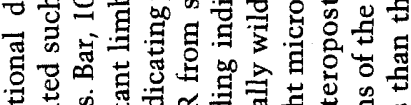
$\varangle$

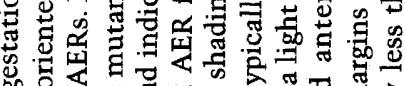

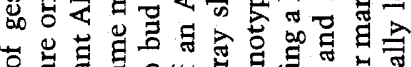

II

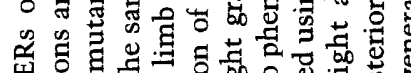

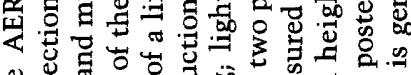

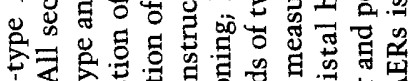

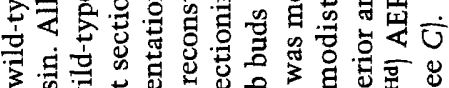

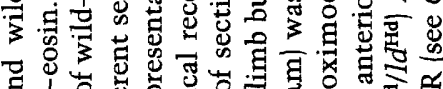

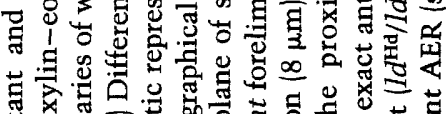

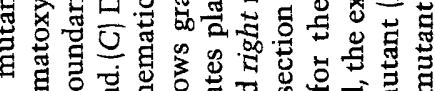

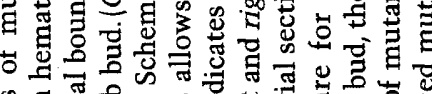

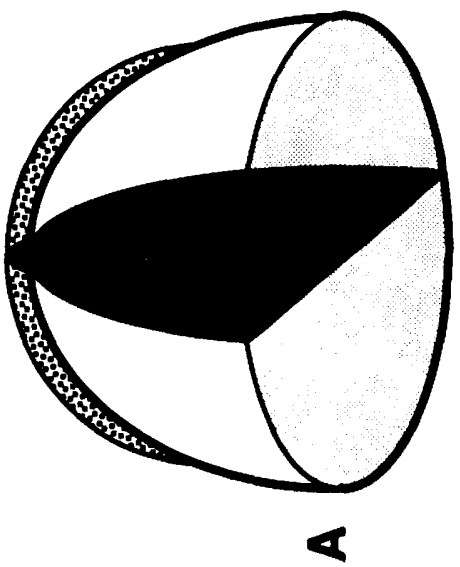

a

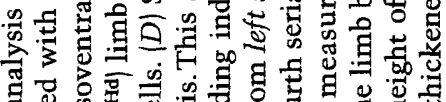

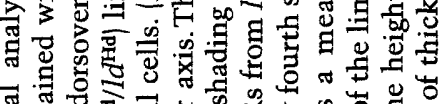
नु 궁

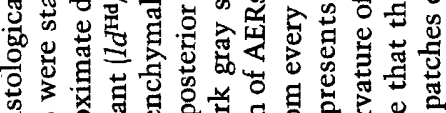

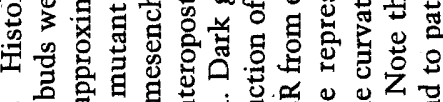

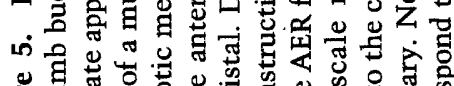

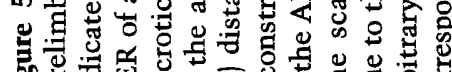

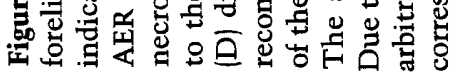


Zeller et al.

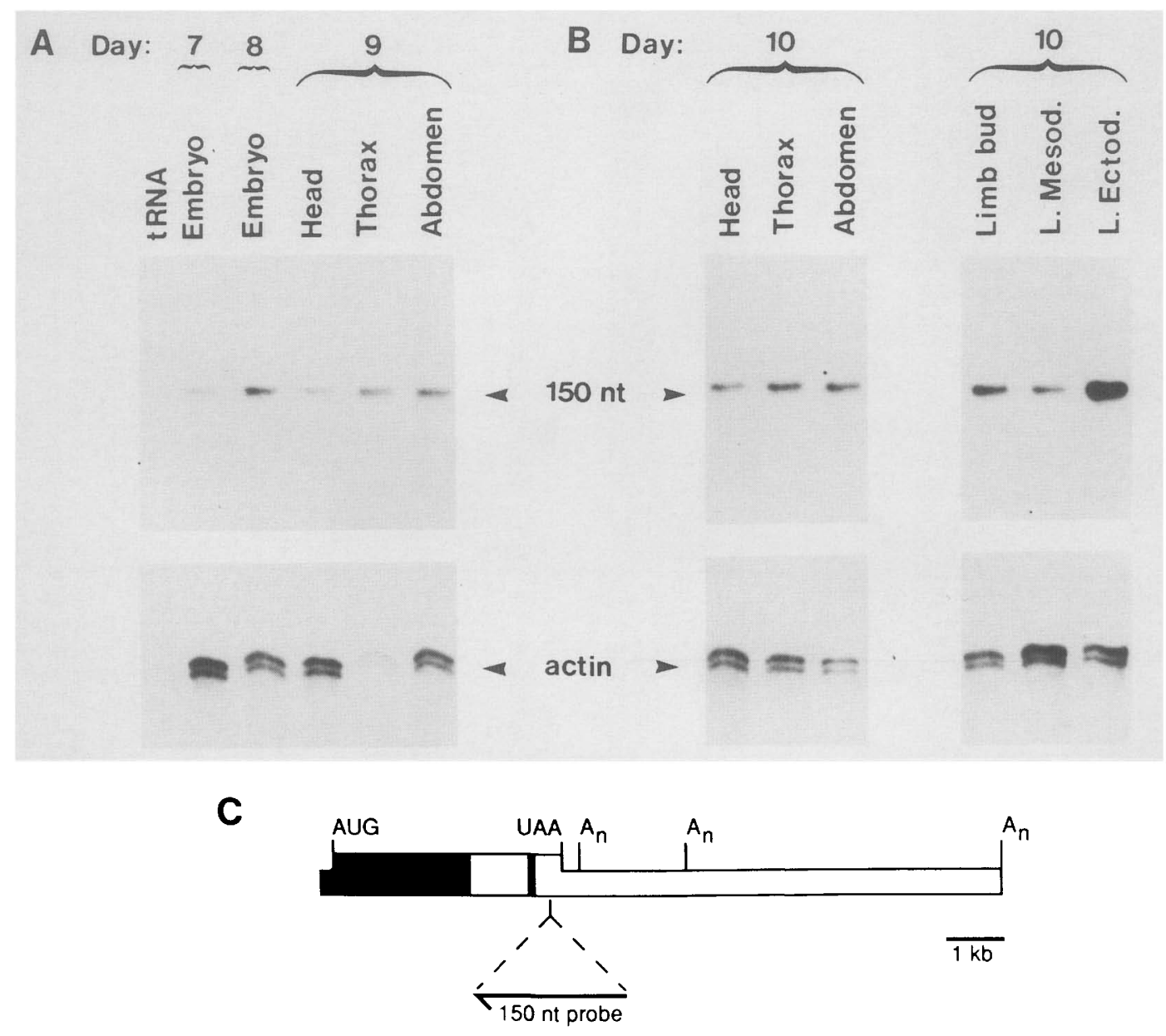

Figure 6. Expression of the $l d$ gene during embryogenesis is higher in limb bud ectoderm than mesenchyme. Expression of the $l d$ gene in embryonic compartments was analyzed by RNase protection assays ( $A$ and $B$ ), using the antisense riboprobe shown in $C$ (see Materials and methods). Total RNA ( $25 \mu \mathrm{g}$ per sample) was hybridized to the $1 d$ antisense probe. (150 nt) A 150-nucleotide fragment is specifically protected by the $l d$ antisense riboprobe. (actin) As a control, total RNA $(5 \mu \mathrm{g}$ ) was hybridized to an antisense actin probe (Spiegelman et al. 1983). Autoradiographic exposure of the $l d$ transcript specific 150-nucleotide protected fragment was 30-fold longer than for actin transcripts. (A) Expression of the Id gene during gestational days 7-9. Gestational day-7 and day-8 embryos were not dissected further. Gestational day-9 embryos were dissected into head (cut below the mandibular arch), thorax (cut below heart and liver bulge), and abdomen (includes tail and limb buds). (B) Expression of the $1 d$ gene in gestational day-10 embryos. Gestational day-10 embryos were dissected into head, thorax, abdomen (includes tail), and limb buds (pooled fore- and hindlimb buds). Limb buds were separated into mesenchymal and ectodermal compartments as described in Materials and methods. (lane L. Mesod.) Limb bud mesoderm; (lane L. Ectod.) limb bud ectoderm. $(C)$ Composite scheme of the $1 d$ transcripts. The identified ORF (AUG to UAA) and three differential polyadenylation sites $\left(A_{n}\right)$ are indicated. Solid areas indicate alternative splicing (R.P. Woychik et al., in prep.). The 150-nucleotide probe is derived from the conserved $3^{\prime}$ part of the ORF and is part of all the major $1 d$ transcripts.

expression found in the mesenchymal compartment cannot be due solely to ectodermal contamination, because the ectodermal compartment represents only a tiny fraction of all limb bud cells (probably $<5 \%$ ). To control for recovery of intact RNA, an actin probe is used as a control in parallel RNase protection assays (Fig. 6, actin).

These results lead to the conclusion that transcription of the $l d$ gene starts much earlier than limb pattern formation and organogenesis. Furthermore, analysis of $l d$ transcripts in limb buds reveals a preferential, but not exclusive, expression of the $1 d$ gene in ectodermal cells. This preferential expression in wild-type ectodermal cells correlates with a failure of the AER to differentiate properly in mutant embryos. Further experiments are needed to determine whether the preferential expression of the $l d$ gene is limited to limb ectodermal cells.

\section{Discussion}

The results of this study show that anteroposterior pattern formation and AER differentiation are affected severely in homozygous $1 d$ embryos, which suggests that normal expression of the $l d$ gene is required for correct AER differentiation and anteroposterior limb pattern formation. This conclusion is based on the assumption that the $1 d$ alleles studied are reduction or loss-of-function mutations. Two lines of experimental evidence 
favor this assumption. First, we have shown that establishment and morphology of the recessive $1 d$ phenotype appears identical in different alleles (for analysis of adult ld mice, see Kleinebrecht et al. 1982; Woychik et al. 1985). Second, transcription of the $1 d$ gene in the mutant $1 d^{\mathrm{Hd}}$ allele is disrupted within an identified ORF / see introductory section), leading to a loss or truncation of at least some of the encoded ld gene products (R. Maas et al., in prep.). Despite these results, we cannot exclude the possibility that a null $l d$ phenotype would be embryonic lethal and that the available $1 d$ alleles represent loss of only one or few of the potential activities of the several $l d$ products.

We detect defects in AER morphology and a shortening of the anteroposterior limb axis during early gestational day 10 . This indicates that $I d$ gene products normally function at or before this time in development. Expression in early primitive streak (gestational day 7) embryos suggests a possible role for the $1 d$ gene in early determinative events controlling limb morphogenesis. Thus, the phenotypic alterations we observe during gestational day 10 may not represent the primary limb defect in mutant $l d$ embryos.

\section{The relationship between AER differentiation and anteroposterior limb pattern formation}

A vital role for the AER in both proximodistal and anteroposterior limb pattern formation has been shown previously (for review, see Fallon et al. 1983). Saunders (1948) showed that removal of the AER leads to severe truncations of the limb pattern in chick embryos. Early removal of an AER from a developing chick wing bud leads to more severe truncations of the proximodistal pattern than late removal (see, Fallon et al. 1983). Rowe and Fallon (1981) showed that partial removal of an AER from developing chick leg buds leads to loss of specific digits (i.e., anteroposterior truncations). A series of anterior to posterior partial AER removals allowed them to map the regions of AER, specifying each of the four leg digits. Taken together, these studies show that the AER is required for outgrowth of the limb bud by maintaining the mesenchyme in a proliferative state. Most likely, local disruption of growth control by the AER leads to the anteroposterior truncations observed by Rowe and Fallon (1981). The effects of the $1 d$ mutation on the anteroposterior limb pattern are very reminiscent of their observations. The reduction in the anteroposterior pattern we observe may also be a consequence of disrupting growth regulation. Therefore, we speculate that the patches of thickened mutant AER (Fig. 5C and E) correspond to regions supporting formation of digit primordia in mutant $l d$ limb buds. The variability in position and size of these patches (Fig. 5D) may explain the variation in truncated digit patterns observed in adults (Kleinebrecht et al. 1982; data not shown).

The results presented in this study lead us to conclude that $l d$ gene products are required for both anteroposterior pattern formation and AER differentiation. This notion is supported further by analysis of two different mouse mutations affecting limb pattern formation: Forsthoefel (1963) studied the semidominant Strong's luxoid (Ist) mutation, which is linked closely to the $1 d$ locus on chromosome 2. Homozygous lst animals display a severe pleiotropic phenotype, including polydactyly of all four limbs. Analysis of limb buds of gestational day-12 homozygous 1 st embryos revealed either elongation or partial duplication of the AER (Forsthoefel 1963). Furthermore, recent genetic evidence suggests that the lst mutation affects the same functional pathway as the $1 d$ mutation (T.F. Vogt and P. Leder, unpubl.). Analysis of the effects of another mouse mutation (meromelia) also showed a correlation between polydactyly of digits or truncations of limbs and hyperor hypoplastic AER morphology. In addition, the morphological changes observed in the underlying mesenchyme suggest that disruption of mesenchymal-ectodermal interactions causes the defects in AER morphology in the latter mutation (Yasuda and Nakamura 1983).

Effects of the ld mutation and retinoic acid on limb morphogenesis

The effects of the $1 d$ mutation on limb bud morphology are similar to some of the effects that retinoic acid has on the chick limb bud. Application of high concentrations of retinoic acid induces truncations of the anteroposterior pattern (Lee and Tickle 1985). Proximal applications to older limb buds induces truncations of both anteroposterior and proximodistal pattern, as well as extensive fusion of limb skeletal primordia (Tickle and Crawley 1988). In addition, flattening of the AER across the entire limb bud, which appears more pointed, occurs in response to applied retinoic acid (Lee and Tickle 1985). During AER flattening, cell density drops and cell shapes change. However, retinoic acid has its primary effect on the mesenchyme and only modulates AER morphology indirectly (Tickle et al. 1989).

In contrast to the indirect effect of retinoic acid on the $\mathrm{AER}$, the fivefold higher level of $l d$ transcripts in the ectoderm suggests to us that the $1 d$ mutation might have a direct effect on the ectodermal compartment forming the AER. Alternatively, it is as likely that $l d$ expression in both mesenchymal and ectodermal compartments is essential for anteroposterior pattern formation and AER differentiation, given the observed perturbations in both the limb bud mesenchyme and AER in ld mutants (Fig. 5).

The ld gene may be part of a group of genes regulating limb morphogenesis

Current models suggest that the two limb compartments communicate by a series of mesenchymal-epithelial interactions (Tickle 1980; Kelley and Fallon 1981; Fallon et al. 1983). These mechanisms seem evolutionarily conserved among higher vertebrates. Given the specific defects we observe in the limb bud mesen- 
chyme and AER of $l d$ mutants, it is reasonable to speculate that the evolutionarily conserved $l d$ gene participates in these mechanisms. Further experiments analyzing mutant $l d$ embryos and embryonic $1 d$ gene products in greater detail will hopefully illuminate the role of the $1 d$ gene in these mechanisms at a molecular level.

Genetic evidence (Grueneberg 1963) suggests that many different genes are involved in limb morphogenesis. Analysis of the temporal and spatial expression pattern of homeo box-containing genes (Oliver et al. 1988, 1989; Dolle and Duboule 1989; Wedden et al. 1989), retinoic acid-binding proteins (Maden et al. 1988), as well as growth factors (Munaim et al. 1988), has implicated the involvement of these elements in limb morphogenesis (for review, see Brockes 1989), but conclusive evidence is still lacking. The $1 d$ gene remains particularly important in that it is a gene directly linked to the morphogenetic pathway through the existence of several mutant alleles that are accessible to cloning and, hence, molecular analysis. The relationship, if any, of the $1 d$ gene to these elements should further our understanding of limb pattern formation and possibly vertebrate morphogenesis, in general.

\section{Materials and methods}

\section{Timing of gestational periods}

Heterozygous females and males of the $1 d^{\text {Hd }}$ (Woychik et al. 1985), ld (Green 1962), ld ${ }^{\text {OR }}$ (Cupp 1960) strains, or wild-type mice were mated, and females checked every morning for vaginal plug formation. The day of vaginal plug formation is defined as gestational day 0 .

\section{Developmental matching of gestational day-10 embryos}

Due to considerable variation in actual developmental stage between different day-10 embryos within the same litter, all embryos were developmentally matched before determination of their respective limb bud phenotype. Developmental matching of embryos was done using a dissecting microscope by comparing their overall size and curvatures, as well as developmental stage of brain, facial structures, and heart (Rugh 1968).

\section{Genotyping of embryos}

Beginning at gestational day 9, embryos were dissected from their deciduas, using watchmaker's forceps, and separated into embryo and extraembryonic membranes. Using a dissecting microscope, the phenotypes of developmentally matched embryos were determined by comparative inspection, as described in Results.

The extraembryonic membranes were collected individually and stored at $-80^{\circ} \mathrm{C}$ until DNA was isolated. DNA was prepared following standard protocols (Maniatis et al. 1982) and dissolved in $75 \mu \mathrm{l}$ (day 9-11) or $150 \mu \mathrm{l}$ (day 12 and older embryos) of $10 \mathrm{~mm}$ Tris (pH 8.0) and $1 \mathrm{~mm}$ EDTA. Two 25- $\mu$ l aliquots of dissolved DNA were denatured in $0.3 \mathrm{M} \mathrm{NaOH}$, neutralized in a fourfold volume of $0.6 \mathrm{M}$ Tris $-\mathrm{HCl}\langle\mathrm{pH} \mathrm{7.5}\rangle$, and 1.5 $\mathrm{M} \mathrm{NaCl}$ and spotted onto separate nitrocellulose membranes (Gelman Sciences), using a dot-blotting apparatus (Schleicher and Schuell). Membranes were baked, and the duplicate filters hybridized to either probe A or B (Fig. 1F).
Genotypes of embryos were determined from their extraembryonic membranes according to the following scheme: The $1 d^{\text {Hd }}$ allele was created by insertion of multiple copies of a transgene carrying pBR322 sequences (probe A, Fig. 1F; for details, see Stewart et al. 1984) and deletion of a stretch of flanking sequences (probe B, Fig. 1F; Woychik et al., in prep.) in chromosome 2 . Therefore, DNA of genotypically homozygous mutant $\left(I d^{\mathrm{Hd}} / 1 d^{\mathrm{Hd}}\right)$ embryos only hybridizes to probe A, whereas wild-type $(+1+)$ DNA only hybridizes to probe $B$. In contrast, heterozygous $\left(1 d^{\mathrm{Hd}} /+\right)$ samples hybridize to both probes (see Fig. 1C). Only embryos whose genotype and phenotype match un mbiguously were studied further.

\section{Fixation and processing of embryos}

For skeletal stains, embryos were fixed and processed as described previously [Alcian green staining (Smith 1980); Alizarin red S/alcian blue staining (McLeod 1980)]. For histological and SEM analysis, embryos were fixed individually in freshly prepared $4 \%$ paraformaldehyde (in $1 \times \mathrm{PBS}$ ) at $4^{\circ} \mathrm{C}$, from 3 (day- 10 and day-11 embryos) to $4 \mathrm{hr}$ (day-12 embryos). For histological sectioning, embryos were embedded in paraplast wax (Monoject Scientific), and sections were stained with hematoxylin-eosin, as described (Zeller 1989). Graphic reconstruction of the AER (Fig. 5D) of mutant and wild-type embryos was done by measuring its maximal proximodistal height in serial sections (Fig. 5), using a light microscope equipped with a micrometer eye piece. For SEM studies, embryos were dehydrated and critical point dried in a Samdri PVT-3B critical point dryer (Tousimis). After mounting, they were coated with palladium-gold, using a Technics Hummer II Spotter Coater. Both critical point drying and coating were done according to manufacturers' instructions. Specimens were viewed using an AMR scanning electron microscope (model 1000).

\section{Separation of mesenchymal and ectodermal compartments of} gestational day-10 limb buds

Fore- and hindlimb buds of gestational day-10 embryos were dissected in Hanks' balanced salt solution $\left(\mathrm{Mg}^{2+}, \mathrm{Ca}^{2+}\right.$ free; HBSS) at $4^{\circ} \mathrm{C}$. Dissected limb buds were pooled in a petri dish and digested at $4^{\circ} \mathrm{C}$ in $2 \%$ trypsin (GIBCO; in HBSS) for $25 \mathrm{~min}$ with gentle shaking. Digestion was terminated by transferring the limb buds into an Eppendorf tube containing 10\% fetal calf serum (FCS) in HBSS $\left(4^{\circ} \mathrm{C}\right)$. The samples were vortexed briefly to separate mesenchymal and ectodermal tissues and inspected visually under a dissecting microscope for complete separation of the two cell layers. Intact limb buds were vortexed again to achieve complete separation. Ectodermal jackets and mesenchymal cones were then separated by serial sorting in petri dishes containing HBSS $\left(+10 \% \mathrm{FCS} ; 4^{\circ} \mathrm{C}\right)$ using a light microscope. To avoid cross contamination, all incompletely separated tissues were removed. Repeated sorting yielded clean ectodermal jackets and mesenchymal cones. Because mesenchymal cones dissociate more easily than ectodermal jackets, a fraction of mesodermal cells were lost, whereas most of the ectodermal cells were recovered. After removal of excess medium, the separated fractions were frozen on dry ice and stored at $-80^{\circ} \mathrm{C}$.

\section{Purification and analysis of embryonic RNA}

Dissected embryonic samples were frozen on dry ice and stored at $-80^{\circ} \mathrm{C}$. RNA was prepared as described by Kingston (1987). To remove traces of contaminating DNA, the RNA was reprecipitated overnight in $1 \mu \mathrm{l}$ of $2.5 \mathrm{M} \mathrm{LiCl}, 0.05 \%$ SDS in $10 \mathrm{M}$ 
Tris- $\mathrm{HCl}(\mathrm{pH} 7.5), 1 \mathrm{~mm}$ EDTA (TE) at $-20^{\circ} \mathrm{C}$. RNA was subsequently dissolved in TE at a concentration of $1-4 \mu \mathrm{g} / \mu \mathrm{l}$ and stored at $-80^{\circ} \mathrm{C}$. RNA concentrations were determined by UV absorption at $260 \mathrm{~nm}$. DNA contamination of RNA samples was determined as described (Labarca and Paigen 1980) and found to be mostly $<1 \%$. To normalize samples for poly $\mid \mathrm{A})^{+}$ RNA concentrations, their content was determined by hybridization to poly $\left[{ }^{3}\right.$ H]UTP (Rosbash and Ford 1974). RNA was analyzed by an RNase protection assay (Melton et al. 1984), using an antisense $\left.{ }^{32} \mathrm{P}\right] \mathrm{UTP}-\mathrm{labeled}$ riboprobe complementary to the major $l d$ transcripts (Fig. 6C) or an antisense $\gamma$-actin probe as a control (pAct-1; Spiegelman et al. 1983).

For quantitative analysis of transcripts in mesenchymal and ectodermal cell layers of gestational day-10 limb buds, RNA of $\sim 750$ fractionated limb buds (see above) was prepared in two independent batches each (combined yields of total RNA: mesenchyme, $840 \mu \mathrm{g}$; ectoderm, $100 \mu \mathrm{g}$ ). Relative levels of $1 d$ transcripts in the two compartments were determined by densitometric scanning of autoradiographs from three independent experiments, using an Ultrascan XL laser densitometer (LKB Bromma). The relative enrichment of $l d$ transcripts in the ectodermal compartment, with respect to the mesenchyme, was calculated (see Results) from these data.

\section{Acknowledgments}

We are grateful to our colleagues Richard Maas, Thomas Vogt, and Richard Woychik for providing materials necessary to do these experiments, as well as for many stimulating discussions and suggestions. We are indebted to Trisha Rice (Museum of Comparative Zoology, Harvard Museum) for excellent technical assistance doing the Scanning EM studies and Daniel Sussman for performing the densitometric scannings. We would like to thank David Altschuler, David Beier, Gregor Eichele, Donna Fekete, Michel Nussenzweig, Norbert Perrimon, Michael Shen, Christina Thaller, and Cheryll Tickle for stimulating discussions and comments on the manuscript. This work is supported, in part, by E.I. Dupont de Nemours, Inc.; R.Z. is the recipient of an EMBO fellowship (1985-1987) and a Swiss National Science Foundation Fellowship (1987-1988). L.J.-G. is the recipient of predoctoral training grant from the National Institutes of Health.

\section{References}

Brockes, J.P. 1989. Retinoids, homeobox genes, and limb morphogenesis. Neuron 2: 1285-1294.

Cupp, M.B. 1960. Mouse news letter 22: 50.

Dolle, P. and D. Duboule. 1989. Two gene members of the murine HOX-5 complex show regional and cell-type specific expression in developing limbs and gonads. EMBO $/$. 8: $1507-1515$.

Fallon, J.F., D.A. Rowe, J.M. Frederick, and B.K. Simandl. 1983. Studies on epithelial-mesenchymal interactions during limb development. In Epithelial-mesenchymal interactions in development (ed. R.H. Sawyer and J.F. Fallon), pp. 3-25. Praeger Scientific, New York.

Forsthoefel, P.F. 1963. The embryological development of the effects of Strong's Luxoid gene in the mouse. I. Morphol. 113: 427-452.

Green, M.C. 1962. Mouse News Letter 26: 34.

- 1968. Mutant genes and linkages. In Biology of the laboratory mouse (ed. E.L. Green), pp. 87-150. Dover Publications, New York.

Grueneberg, H. 1963. The pathology of development. A study of inherited skeletal disorders in animals. Blackwell Scientific Publications, Oxford.

Kelley, R.O. and J.F. Fallon. 1981. The developing limb: An analysis of interacting cells and tissues in a model morphogenetic system. In Morphogenesis and pattern formation, (ed. T.G. Connelly et al.), pp. 49-85. Raven Press, New York.

Kingston, R.E. 1987. Guanidinium method for total RNA preparation. In Current protocols in molecular biology, (ed. F.M. Ausubel, et al.), vol. 1, pp. 4.2.1-4.2.5. Greene Publishing Associate and Wiley-Interscience, New York.

Kleinebrecht, J., J. Selow, and W. Winkler. 1982. The mouse mutant limb-deformity (ld). Anat. Anz. 152: 313-324.

Kochhar, D.M. 1977. Abnormal organogenesis in the limb. In Handbook of teratology, (ed. J.G. Wilson and F.C. Fraser), pp. 453-479. Plenum Press, New York.

Labarca, C. and K. Paigen. 1980. A simple, rapid, and sensitive DNA assay procedure. Anal. Biochem. 102: 344-352.

Lee, J. and C. Tickle. 1985. Retinoic acid and pattern formation in the developing chick wing: SEM and quantitative studies of early effects on the apical ectodermal ridge and bud outgrowth. I. Embryol. Exp. Morph. 90: 139-169.

Maden, M., D.E. Ong, D. Summerbell, and F. Chytil. 1988. Spatial distribution of cellular protein binding to retinoic acid in the chick limb bud. Nature 335: 733-735.

Maniatis, T., E.F. Fritsch, and J. Sambrook. 1982. Molecular cloning: A laboratory manual. Cold Spring Harbor Laboratory, Cold Spring Harbor, New York.

McLeod, M.J. 1980. Differential staining of cartilage and bone in whole mouse fetuses by alcian blue and alizarin red $S$. Teratology 22: 299-301.

McNeish, J.D., W.J. Scott Jr., and S.S. Potter. 1988. Legless, a novel mutation found in PHT1-1 transgenic mice. Science 241: 837-839.

Melton, D.A., P.A. Krieg, M.R. Rebagliati, T. Maniatis, K. Zinn, and M.R. Green. 1984. Efficient in vitro synthesis of biologically active RNA and RNA hybridization probes from plasmids containing a bacteriophage SP6 promoter. Nucleic Acids Res. 12: 7035-7056.

Munaim, S.I., M. Klagsbrun, and B.P. Toole. 1988. Developmental changes in fibroblast growth factor in the chicken embryo limb bud. Proc. Natl. Acad. Sci. 85: 8091-8093.

Oliver, G., C.V.E. Wright, J. Hardwicke, and E.M. De Robertis. 1988. A gradient of homeodomain protein in developing forelimbs of Xenopus and mouse embryos. Cell 55: 10171024.

Oliver, G., N. Sidell, W. Fiske, C. Heinzmann, T. Mohandas, R.S. Sparkes, and E.M. De Robertis. 1989. Complementary homeo protein gradients in developing limb buds. Genes Dev. 3: 641-650.

Rosbash, M. and P.J. Ford. 1974. Polyadenylic acid-containing RNA in Xenopus laevis oocytes. I. Mol. Biol. 85: 87-101.

Rowe, D.A. and J.F. Fallon. 1981. The effect of removing posterior apical ectodermal ridge of the chick wing and leg on pattern formation. I. Embryol. Exp. Morph. 65: 309-325.

Rugh, R. 1968. The mouse. Its reproduction and development. Burgess Publishing, Minneapolis.

Saunders, I.W. 1948. The proximodistal sequence of origin of the parts of the chick wing and the role of the ectoderm. $J$. Exp. Zool. 108: 363-403.

Smith, J.C. 1980 . The time required for positional signalling in the chick wing bud. I. Embryol. Exp. Morphol. 60: 321-328.

Spiegelman, B.M., M. Frank, and H. Green. 1983. Molecular cloning of mRNA from 3T3 adipocytes. Regulation of mRNA content for glycerophosphate dehydrogenase and other differentiation dependent proteins during adipocyte 
Zeller et al.

development. J. Biol. Chem. 258: 10083-10089.

Stewart, T.A., P.K. Pattengale, and P. Leder. 1984. Spontaneous mammary adenocarcinomas in transgenic mice that carry and express MTV/myc fusion genes. Cell 38: 627-637.

Thaller, C. and G. Eichele. 1987. Identification and spatial distribution of retinoids in the developing chick limb bud. $\mathrm{Na}$ ture 327: 625-628.

Tickle, C. 1980. The polarizing region and limb development. In Development in mammals, (ed. M.H. Johnson), vol. 4, pp. 101-136. Elsevier/North-Holland Biomedical Press, Amsterdam.

Tickle, C. and A. Crawley. 1988. The effects of local application of retinoids to different positions along the proximodistal axis of embryonic chick wings. Wilhelm Roux's Arch. Dev. Biol. 197: 27-36.

Tickle, C., A. Crawley, and J. Farrar. 1989. Retinoic acid application to chick wing buds leads to a dose-dependant reorganisation of the apical ectodermal ridge that is mediated by the mesenchyme. Dev. Biol. (in press).

Tickle, C., J. Lee, and G. Eichele. 1985. A quantitative analysis of the effect of all trans retinioc acid on the pattern of chick wing development. Dev. Biol. 109: 82-95.

Tickle, C., G. Shellswell, A. Crawley, and L. Wolpert. 1976. Positional signalling by mouse limb polarising region in the chick wing bud. Nature 259: 396-397.

Wedden, S.E., K. Pang, and G. Eichele. 1989. Expression pattern of homeobox-containing genes during chick embryogenesis. Development 105: 639-650.

Wolpert, L. 1969. Positional information and the spatial pattern of cellular differentiation. I. Theor. Biol. 25: 1-47.

Woychik, R.P., T.A. Stewart, L.G. Davis, P. D'Eustachio, and P. Leder. 1985. An inherited limb deformity created by insertional mutagenesis in a transgenic mouse. Nature 318: $36-$ 40.

Yasuda, M. and H. Nakamura. 1983. Pathogenesis of limb malformations in mice: An electron microscope study. In Limb development and regeneration, Part $\mathrm{A}$, (ed. J.F. Fallon and A.I. Caplan), pp. 301-310. Alan R. Liss, New York.

Zeller, R. 1989. Fixation, embedding, and sectioning of tissues, embryos, and single cells; Counterstaining and mounting of autoradiographed in situ hybridization slides. In Current Protocols in Molecular Biology, (ed. F.M. Ausubel et al.), vol. 2, pp. 14.1.1-14.5.4. Greene Publishing Associates and Wiley-Interscience, New York. 


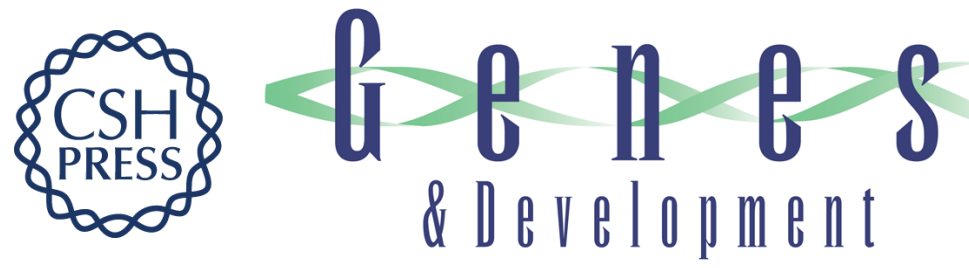

\section{The limb deformity gene is required for apical ectodermal ridge differentiation and anteroposterior limb pattern formation.}

R Zeller, L Jackson-Grusby and $\mathrm{P}$ Leder

Genes Dev. 1989, 3:

Access the most recent version at doi:10.1101/gad.3.10.1481

References This article cites 28 articles, 5 of which can be accessed free at:

http://genesdev.cshlp.org/content/3/10/1481.full.html\#ref-list-1

License

Email Alerting

Service

Receive free email alerts when new articles cite this article - sign up in the box at the top right corner of the article or click here.

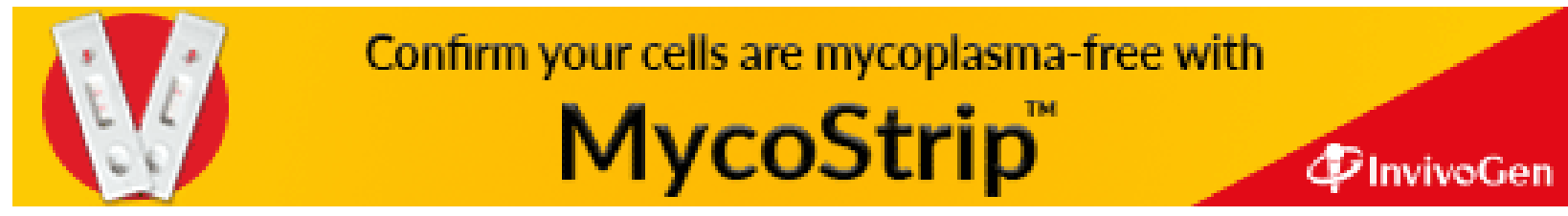

